\title{
Agro-industrial uses of glycinebetaine
}

\section{Mäkelä, Pirjo}

2005

Mäkelä, P 2005 , ' Agro-industrial uses of glycinebetaine ' , Sugar Tech , vol. 6 , no. 4 , pp. 207-212.

http://hdl.handle.net/10138/312331

submittedVersion

Downloaded from Helda, University of Helsinki institutional repository.

This is an electronic reprint of the original article.

This reprint may differ from the original in pagination and typographic detail.

Please cite the original version. 


\title{
Agro-Industrial Uses of Glycinebetaine
}

\author{
Pirjo Mäkelä \\ Department of Applied Biology, P.O. Box 27, 00014 University of Helsinki, Finland
}

\begin{abstract}
In addition to sugar, several different compounds are presently separated from beet molasses and juices. Nowadays, some of these products have proved to be economically even more important to beet sugar factories than the original product, sugar. One of these compounds is glycinebetaine (N, N', N"trimethylglycine, GB), an amino acid derivative accumulated in many microbes and plant species grown under stress, but also in humans. Especially halophytes belonging to families Amaranthaceae, Asteraceae, Chenopodiaceae, Convolvulaceae, Graminaceae, Malvaceae, Poaceac and Portulaceae synthesize and accumulate GB. GB is assumed to have several adaptive effects on drought and salt stressed plants according to studies mostly based on research work established with cell cultures, bacteria, or isolated chloroplasts. The known role of GB is to maintain water content in animal and piant cells by lowering solute potential under osmotic stress, i.e. to act in osmotic adjustment. This has offered a wide field for use of GB in industry and agriculture for various purposes.
\end{abstract}

KEYWORDS : Glycinebetaine, crop production, sugarbeet molasses

At a certain point of sugar processing no more sugar can be crystallized from molasses which contain virtually all of the original GB. Therefore, molasses is used as a raw material for the production of GB. The extraction is based on chromatographic separation process. This process is carried out in large columns filled with separation resin (Fig. 1). Water is used to elute the molasses through the column system. At the outlet points of the column system, the different compounds, like GB, can be collected as almost pure solutions. These are concentrated and crystallized into pure natural, anhydrous GB. The other source for industrially purified non-synthetic GB is marine brown algae Ascophyllum nodosum (L.) Le Jol. (Whapman et al., 1993; Blunden et al., 1997). Synthetic GB is also available from Sigma chemical company.

Sugar beet (Beta vulgaris L. v. altissima) is a crop species grown in northern latitudes that accumulates GB also when no stresses occur. The $G B$ concentration in sugar beet is especially dependent on the variety. Old varieties usually contain more GB than the new ones, as breeding has been targeted for better extraction of sugars through

Author for Correspondence : Pirjo Mäkelä

e-mail : pirjo.makela@helsinki.fi reducing compounds such as GB. Water shortages and low plant canopy density during the growing period result in increased rate of GB accumulation in sugar beet (Beiß, 1994). Furthermore, a high positive correlation exists between increased potassium fertilizer application rate and $\mathrm{GB}$ concentration in sugar beet root. Moreover, GB concentration is known to increase towards the end of the growing season being highest in the upper parts of the sugar beet storage root (Beringer et al., 1986; Beiß, 1994).

In Chenopods including sugar beet, $G B$ is synthesized (Fig. 2) by a two step oxidation pathway of choline in the chloroplast (McCue and Hanson, 1990). The first step is catalysed by choline monooxygenase (CMO) and results in hydrate form of betaine aldehyde. The next step is synthesis of betaine which is catalyzed by betaine aldehyde dehydrogenase (BADH) (Broquisse et al., 1989). The choline for GB syntinesis is formed from serine which in turn is an intermediate product of photo-oxidative carbon metabolism and photorespiration (Papageorgiou et al., 1991). It has been postulated that light is essential for the synthesis of GB as the first step requires reduced ferredoxin (Arakawa et al., 1992). McCue and Hanson (1990) have suggested that the enzyme activities in GB synthesis are regulated possibly by osmotic stress. However, in 


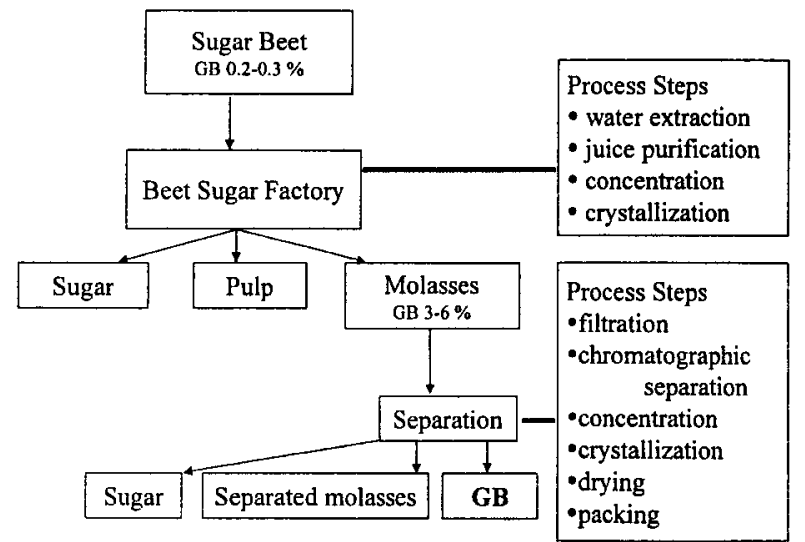

Fig. 1: The method of GB separation in sugar processing from sugar beets.

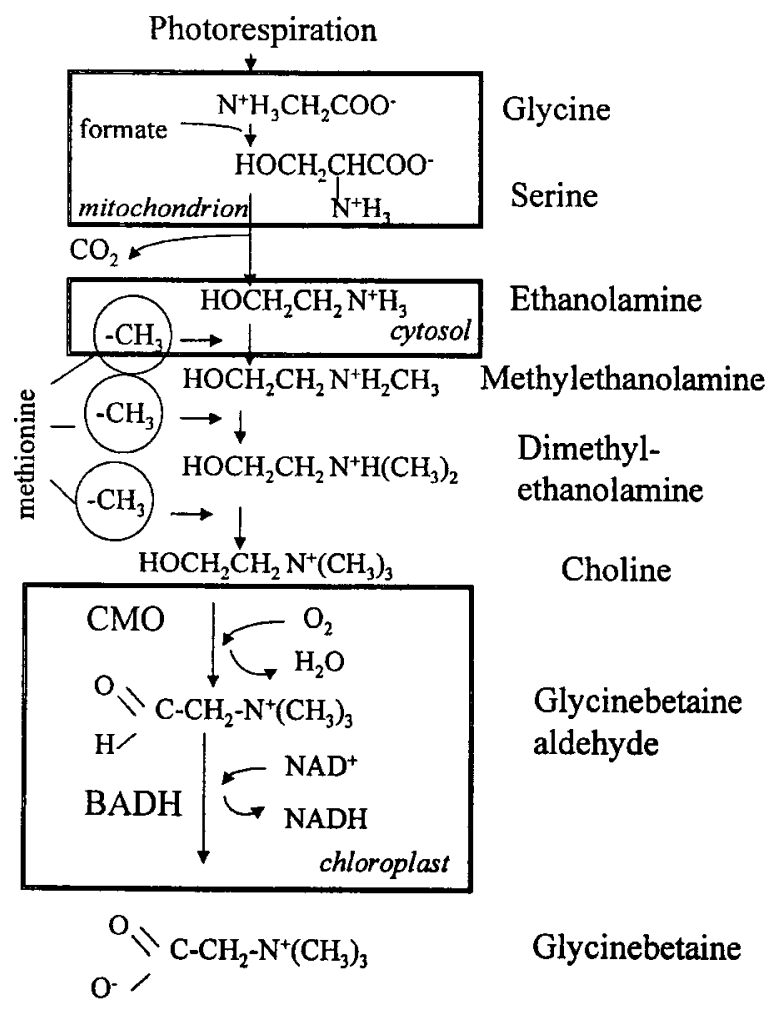

Fig. 2. The proposed pathway of GB synthesis in chenopods (including sugar beet) after Wyn Jones and Storey (1981), Hanson and Grumet (1985), Hanson et al. (1995) and Gorham (1995). CMO, choline mono-oxygenase; BADH betaine aldehyde dehydrogenase.

sugar beet the signal that causes the rise in BADH mRNA is still under investigation (Hanson et al., 1995). It does not seem to be reduction in turgor, accumulation of $\mathrm{NaCl}$ in plant tissue nor abscisic acid (ABA) but some biochemical factor translocated from roots to shoot. The oxidation steps are physiologically irreversible and the end product, GB, metabolically quite inert in plants (Hanson and Grumet, 1985). The synthesis of GB for plants is, however, energetically expensive as it requires nitrogen, and the biosynthetic pathway is dependent on NADPH as reducing power (Gorham, 1995).

\section{GLYCINEBETAINE IN ANIMAL PRODUCTION}

In a volumetric scale, application of GB for animal nutrition is globally the largest. The use of $\mathrm{GB}$ in animal feed is based on its two metabolic roles in animals as a methyl donor and an osmolyte. GB molecule has three methyl groups. One of those is labile and primarily used to methylate homocysteine to methionine (Finkelstein, 1990). Two other methyl groups of GB are transferred to folate providing an alternative route for homocysteine methylation (Frontiera et al., 1994). Although GB is synthesized endogenously from choline in most animal tissues it does not seem to be sufficient for the needs of methylation, especially when environmental factors such as pathogen challenge affect the need of methionine. This has been demonstrated with chicken as $40-50 \%$ of the choline requirement and 20-25\% of the methionine requirement in diet could be replaced with GB supplementation (Frontiera et al., 1994).

The osmolytic function of $G B$ in animal metabolism is maintenance of the osmotic strength of cells and stabilization of macromolecular functions. GB has been shown to improve water retention in the epithelium of hyperosmotically stressed chicken small intestine. Actually, GB supplementation has been used for many years to relieve osmotic stress of salmonid fish when transferred from fresh water to sea water (Clarke $e t$ al., 1994). Moreover, orally given $G B$ has been reported to relieve diarrhea and dehydration in various animals as well as inhibit the invasion of coccidian (Eimeria sp.) parasite into gut epithelium (Ferket, 1994; Augustine and McNaughton, 1996).

The lipotropic property of GB as a methyl donor (Saunderson and Mackinlay, 1990; Barak et al., 1993) has been utilized especially in the animal industry in order to reduce carcass fat and prevent excess accumulation of fat into the liver.

\section{GLYCINEBETAINE IN CROP PRODUCTION}

The role of quaternary ammonium (QAC) and tertiary sulfonium (TSC) compounds as nontoxic compatible solutes has been recognized for years in studies of plant adaptation to saline or dry environments (Rhodes and Hanson, 1993). GB is the most studied of these compounds (Hanson et al., 1995). The reason for that may lie in the nature of $G B$ as it does not inhibit enzymes even at high concentrations (Papageourgiou and Murata, 1995). Therefore, it can be accumulated in the cytoplasm of plant cells to contribute to the osmotic balance between the cytoplasm and vacuole without causing any damages. This unique nature of $G B$ has led to that that sugar beet molasses derived foliar-applied GB is widely used in crop production throughout the world for different purposes. It is used for increasing the cold resistance of e.g. potatoes in the 
early spring, to increase the drought and salt resistance of e.g. tomatoes and pruning and for many other purposes. It is also used to lengthen the storage life of iceberg lettuce (Hurme et al., 1999). Genetic engineering of endogenous GB in crop plants has been the focus of several groups. However, exogenous applications of GB have proven so far more effective means of crop manipulation since, the genetically engineered synthesis of GB has not yet succeeded satisfactorily (Huang et al., 2000; McNeil et al., 2000).

Although exogenously applied GB may be metabolized by micro-organisms soon after application (Gorham, 1995), encouraging results have been obtained with foliar- (Agboma et al., 1997a,b; Mäkelä et al., 1996b, 1997) and root-applied (Hofinger et al., 1976) GB. In spite of e.g. the risk of microbes utilizing exogenously applied GB, foliarapplied $G B$ is readily taken up and translocated within hours to roots and developing leaves probably along with assimilation products (Mäkelä et al., 1996a). It is even translocated from roots to soil and thereafter to other plants (unpublished). However, the rate of uptake and consequent $G B$ concentration in the plant tissue seem to be not only dependent on plant organ and its age but also on crop species and environmental factors (Mäkelä et al., 1996a). Coapplication of surfactant, vegetable oils in particular, tends to increase uptake by GB probably due to faster rate of uptake and thus minimizing the risk of rain flushing the GB off of the leaf foliage. Moreover, the droplets formed are smaller in size and the wax layers on the leaf surface are modified by most surfactants used thus enabling faster rate of uptake (Mäkelä et al., 1996a).

$\mathrm{GB}$ is regarded as rather inert compound (Gorham, 1995), but there are however some opposite indications. For example, alfalfa (Medicago sativa L.) and its rhizobia (Rhizobium meliloti $102 \mathrm{~F} 34$ ) have been reported to be able to catabolise GB (Pocard et al., 1991). However, it is not known which microbes existing in soil and on the leaf surface are able to catabolise GB and to what extent (Gorham, 1995). Endogenously accumulated $G B$ has also been reported to attract, and thereby to increase the survival rate and reproduction of aphids and plant pathogens (Araya et al., 1991; Zuniga, 1989). Thus, it might be possible that exogenously applied GB also attracts and increases the rate of plant pathogens and insects in treated plants and hence, decreases realization of the yield potential. However, contrasting results have also been reported. According to Whapman et al. (1993) there are indications of increased resistance of $\mathrm{GB}$ treated wheat against Puccinia recondite tritici Eriks. \& Henn. Also, tomato cultivars treated with GB showed increased resistance against Meloidogyne javanica and $M$. incognita nematodes (Wu et al., 1997).
The earliest experiments with exogenous $G B$ in plant production were conducted by Hofinger et al. (1976) and by Itai and Paleg (1982). According to Hofinger et al. (1976) GB behaved as a strong inhibitor of root growth when applied at higher concentrations than $50 \mathrm{mM}$ on the growth medium of lentil, although it stimulated the growth of roots when applied at concentrations between $1 \mathrm{mM}$ and $50 \mathrm{mM}$. Itai and Paleg (1982) reported increased growth of drought-recovering barley (Hordeum vulgare L.) when GB (25 $\mathrm{mM})$ was applied on the leaf foliage of stressed plants towards the end of the stress period.

Field experiments conducted in drought-prone environments and in saline soils have indicated that the crop stability and yield was often increased due to foliar applications of $G B$ when sprayed prior to stress. For example, shoot growth and seed yield exposed to drought stress were increased by $8 \%$ when $3 \mathrm{~kg} \mathrm{ha}^{-1} \mathrm{~GB}$ was applied to soybean (Glycine max L. Merr.) (Agboma et al., 1997b). There has also been indications of GB treatment induced increases in mean above-ground biomass production and grain yield up to $25 \%$ in maize (Zea mays L.), and by up to $11 \%$ in sorghum [Sorghum bicolor (L.) Moench] when plants were suffering from drought. Increase in grain yield was due to increased grain set and reduced abortion, i.e. more grains per head whereas single grain weight was unaffected (Agboma et al., 1997a). Furthermore, field experiments conducted in California have indicated that the fruit yield of tomato plants increased by 29-39\% under heat and salt stress when GB was applied during the mid flowering stage. Similar trends with approximate increase of $20-30 \%$ have been obtained in experiments conducted in the greenhouse of commercial vegetable grower in Finland but with unstressed tomato plants (Mäkelä et al., 1998a).

The explanation to the yield increases of stressed tomato plants after application of GB has been proposed to lie at least partly in the increased net photosynthesis and decreased rate of photorespiration. Moreover, increased stomatal conductance (Mäkelä et al., 1998b) might have induced more efficient gas exchange and thus, better availability of carbon for photosynthetic processes and ability to avoid possibly photoinhibition (Mäkelä et al., 1999)without any disturbance in ABA content (Mäkelä et al., 1998b). According to Bergmann and Eckert (1984) $20 \mathrm{mM}$ application of glycinebetaine to roots increased the net photosynthesis and water use efficiency of winter wheat, resulting in increased number of fertile florets and grains per plant. Similar results on increased net photosynthesis have been obtained with stressed tomato (Lycopersicon esculentum Mill.) and turnip rape (Mäkelä et al., 1999). Actually, the sustainability of photosynthetic efficiency achieved with exogenous $G B$ has been explained later by $\mathrm{GB}$ induced maintenance of 
chloroplast ultrastructure (Mäkelä et al., 2000) and chloroplast volume (Rajasekaran et al., 1997). Furthermore, Whapman et al. (1993) and Blunden et al. (1997) reported increased chlorophyll content in plants treated with seaweed extract containing GB. However, the mechanism to these changes is not known even yet. Several studies with bacteria and isolated chloroplasts indicate that GB protects, stabilizes and activates the proteins of photosynthetic reactions (Papageourgiou and Murata, 1995).

\section{GLYCINEBETAINE FOR INDUSTRIAL PURPOSES}

Due to the unique nature of GB molecule it has been exploited in several industrial applications developed in recent years, such as in pharmaceuticals, cosmetics, fermentation and cell cultures (Fig. 3). In the cosmetic industry there is an increasing demand for safety, non-irritating and non-sensitising raw materials. GB is non-mutagenic and non-allergenic compound which has an amphoteric character and conditioning properties. Moreover, it has a moisturizing effect by improving moisture retention of the skin and produces reduction in the irritation potential. Since, the molecule is non-toxic, hygroscopic and osmoprotective its properties are desired. Accordingly, it is nowadays used in skin creams and ointments, medicated cleansers, syndets, after shave lotions and deodorants.

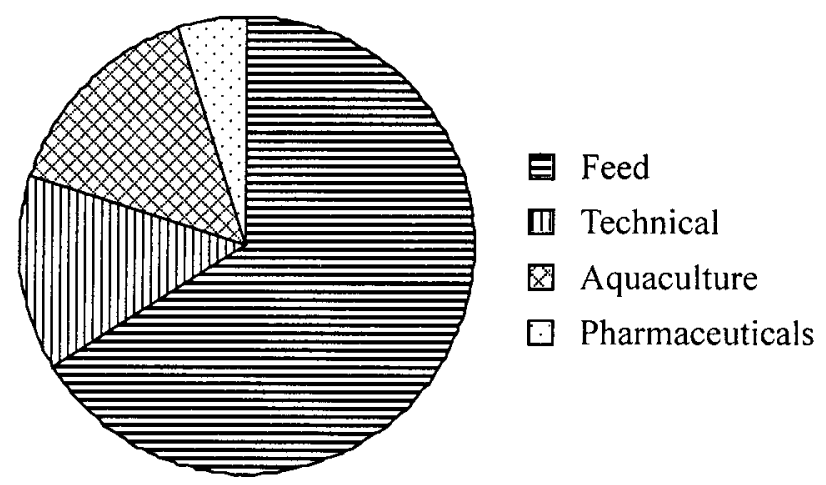

Fig. 3 : The utilization of GB (produced by Danisco in Finland) for different purposes in agriculture and industry.

Traditionally GB has been used in pharmaceutical industry primarily to prevent disturbances in liver methionine metabolism. This is typically a result of e.g. excess intake of alcohol causing fat accumulation into liver, i.e. so called 'fatty liver' (Barak et al., 1993). Another application of GB in pharmaceutical industry is in a treatment of a metabolic disease 'homocystinurea' caused by an inefficient recirculation of homocysteine to methionine. Besides the disease many people have elevated levels of homocysteine in the blood which may increase the risk for coronary diseases (Dudman et al., 1993). Most mammalian membranes contain choline which is probably an essential nutrient for humans and acetylcholine present in neurons and placenta as a neurotransmitter. GB is a choline metabolite and important methyl donor for the regeneration of methionine from homocyateine. A deficiency of choline in neonates leads to a respiratory distress syndrome in premature infants. Infants usually get choline in the milk of maternal blood. Thus, GB could be added to the milk in order to avoid choline deficiency. Moreover, supplemental choline exposure during the prenatal period has been reported to alter permanently the brain structure and improve the memory function of rats (Rohlfs et al., 1993).

In the fermentation industry, $G B$ is used as a methyl donor and metabolic regulator. It has been shown to relieve osmotic stress and improve yield of lysine-producing Brevibacterium lactofermentum (Kawahara et al., 1990). It has been possible to increase the survival and growth rate of bacteria adding GB to the culture medium (Kets and de Bont, 1994). The role of GB has been putative also in embryo cultures, as these are needed in breeding programs. As GB addition has increased the growth and survival rate of cultured and isolated cells, GB is used widely as a practice in cell isolation and culture media nowadays.

\section{CONCLUSIONS}

GB, an additional product from sugar beet processing industry, has for long been used in applications of pharmaceutical and feed industry. The use of GB in animal feed is based on its metabolic role in animals both as methyl donor and an osmolyte. Supplemental GB can help animal cells to maintain osmotic balance when exposed to heat and other osmotic disturbances. Another application of GB studied intensively during the last decade is the possibility to enhance crop growth and productivity under water, salt and cold stresses. The physiological basis of yield increases is still under investigation but there are implications that GB might affect the reproductive sterility of cultivated plants. The data indicates also that plant species and even cultivars differ in response to foliar-applied GB. Environmental conditions and plant species also affect the uptake and translocation markedly but environmental factors interact also with genotype causing differences in crop's responsiveness to applied GB. In conclusion, the previously called waste product and processing problem, GB, has proved to be very worthy in comparison to the sugar itself.

\section{ACKNOWLEDGEMENTS}

Drs. Erkki Virtanen and Kari Jokinen and Prof. Pirjo Peltonen-Sainio are thanked for constructive comments and suggestions. 


\section{EFERENCES}

gboma, P., Jones, M.G.K., Peltonen-Sainio, P., Rita, H. and shu, E. (1997a). Exogenous glycinebetaine enhances grain eld of maize, sorghum and wheat grown under two pplementary watering regime. J. Agron. and Crop Sci., 178 $1-37$.

gboma, P., Sinclair, T.R., Peltonen-Sainio, P., Jokinen, K. id Pehu, E. (1997b). An evaluation of the effect of foliar plication of glycinebetaine on the growth and yield of soybean: ning of application, watering regimes and cultivars. Field ops Res., 54: 51-64

-akawa, K., Mizuno, K., Kishitani, S. and Takabe, T. (1992). imunological studies of betaine aldehyde dehydrogenase in rley. Plant Cell Phys., 33: 833-840.

aya, F., Abarca, O., Zuniga, G.E. and Corcuera, L.J. (1991). fects of $\mathrm{NaCl}$ on glycinebetaine and on aphids in cereal zdlings. Phytorhemistry. 30: 1793-1795.

Igustine, P. and McNaughton, J.L. (1996). Effect of betaine invasion and development of the avian coccidian and growth rformance in coccidian-infected chicks. Proceedings of the uryland Nutrition Conference. March 21-22. pp. 31-36.

rak, A.J., Beckenhauer, H.C., Junnila, M. and Tuma, D.J. 993). Dietary betaine promotes generation of hepatic Ssnosylmethionine and protects the liver from ethanol-induced ty infiltration. Alcoholism: Clinical Exp. Res., 17 : 552-555.

iß, U. (1994). Zum Betaingehalt der Zuckerrübe. ckerindustrie, 119: 112-117.

rgmann, H. and Eckert, H. (1984). Einfluß von Glycinbetaine $f$ die Wasserausnutzung von Winterweizen Triticum aestivum Bul Plantarum, $26: 384-387$.

ringer H., Koch $K$. and Lindhauer M.G. (1986). Sucrose :umulation and potassium potentials in sugar beet at mereasing els of potassium nutrition. Journal of Science of Food and riculture. $37: 211-218$.

Inden, G., Jenkins, T. and Liu, Y.W. (1997). Enhanced leaf orophyll levels in planta treated with seaweed extract. J. Appl. vcol.. $8: 535-543$

oquisse, R., Weigel, P., Rhodes, D., Yocum, C.F. and Hanson, J. (1989). Evidence for ferredoxin-dependent choline monorgenase from spinach chloroplast stroma. Plant Physiol., 90 $22-329$

irke, W.C., Virtanen, E., Blackburn, J. and Higgs, D.A. 94). Effects of a dietary betaine/amino acid derivative on wth and seawater adaptation in yearling Chinook salmon. aculiure. $121 \cdot 137-145$.

dman, N.P.B., Wilcken, D.E.L., Wang, J., Lynch, J.F., cey, D. and Lundberg, P. (1993). Disordered methionine/ nocysteine metabolism in premature vascular disease. erioscler: Thromb. 13: 1253-1260.

'kct, P.R. (1995). Flushing syndrome in the grow-out stage zommercial turkeys. Proceedings of the Smithkline Beecham imal Health Pacesetter Seminar January $10^{\text {th }} 1995$ in Orlando. rida. pp. 1-7.

Ikelstein, J.D., Martin, J.J. and Harris, B.J. (1988). thionine metabolism in mammals. J. Biol. Chem., 263 : 11750'54.

inticra, M.S., Stabler, S.P., Kolhouse, J.F. and Allen, R.H. 94). Regulation of methionine metabolism: effect of nitrous de and excess methionine. I. Nutr. Biochem., 5 : 28-38.

ang, J., Hirji, R., Adam, L., Rozwadowski, K.L., mmerlindl, J.K., Keller, W.A. and Selvaraj, G. (2000). letic engineering of glycinebetaine production toward ancing stress tolerance in plants. metabolic limitations. Plant siol, $122: 747.756$.
Hurme, E.U., Kinnunen, A., Heiniö, R.L., Ahvenainen, R. and Jokinen, K. (1999). The storage life of packed shredded iceberg lettuce dipped in glycine betaine solutions. J. Food Protect, 62 : 363-367.

Kawahara, Y., Yoshihara, Y., Ikeda, S., Yoshii, H. and Hirose, Y. (1990). Stimulatory effect of glycinebetaine on L-lysine fermentation. Appl. Microbiol. Biotechmol, 34: 87-90.

Kets, E.P.W. and de Bont, J.A.M. (1994). Protective effect of betaine on survival of Lactobacillus plantarum subjected to drying. FEMS Microbiol. Lett., 116 : 251-256.

Gorham J. (1995). Betaines in higher plants - biosynthesis and role in stress metabolism. Aminoacids and Their Derivatives in Higher Plants (ed. Wallgrove, R.M.) University Press, Cambridge, pp. 172-203.

Hanson, A.D., Rivoal, J., Burnet, M. and Rathinasapabathi, B. (1995). Biosynthesis of quaternary ammonium and tertiary sulphonium compounds in response to water deficit. Environment and Plant Metabolism. Flexibility and Acclimation (ed. Smirnoff, N.) BIOS Scientific Publishers Lıd, Oxford, pp. 189-198.

Hanson, A.D. and Grumet, R. (1985). Betaine accumulation: metabolic pathways and genetics. Cellular and Molecular Biology of Plant Stress (eds. Kent, J.L. and Kosuge, T.) Alan R Liss Inc, New York, pp. 71-92.

Hofinger, M., Coumans, M., Ceulemans, E. and Gaspar, T.H. (1976). Assigning a biological role to hypaphorine and lycine (two betaines). Planta Medica, $30: 303-309$.

Itai, C. and Paleg, L.G. (1982). Responses of water-stressed Hordeum distichum $\mathrm{L}$. and Cucumis sativus to proline and betaine. Plant Sci. Lett., $25:$ 329-335

Mäkelä, P., Jokinen, K., Peltonen-Sainio, P., Pehu, E., Setälä, H., Hinkkanen, R. and Somersalo, S. (1996a). Uptake and translocation of foliarly applied glycinebetaine in crop plants. Plant Sci., 121: 221-230.

Mäkelä, P., Jokinen, K., Kontturi, M., Peltonen-Sainio, P., Pehu, E. and Somersalo, S. (1998a). Foliar application of glycinebetaine - a novel product from sugar beet - as an approach to increase tomato yield. Ind. Crops and Prod., 7 . 139-148.

Mäkelä, P., Kleemola, J., Jokinen, K., Mantila, J., Pehu, E. and Peltonen-Sainio, P. (1997). Growth response of pea and summer turnip rape to foliar application of glycinebetaine. Acta Agric. Scand.. Sect B, Soil and Plant Sct.. 47: 168-175.

Mäkelä, P., Kontturi, M., Pehu, E. and Somersalo, S. (1999). Photosynthetic response of drought- and salt-stressed tomato and turnip rape plants to foliar-applied glycinebetaine. Phys Plantarum, $105: 45-50$

Mäkelä, P., Kärkkäinen, J. and Somersalo, S. (2000). E⿶fect of glycinebetaine on chloroplast ultiastructure, chlorophyll and protein content, and RuBCO activities in tomato grown under drought or salinity. Biol. Plantarum, 43:471-475.

Mäkelä, P., Mantila, J., Hinkkanen, R., Pehu, E. and PeltonenSainio, P. (1996b). Effect of foliar applications of glycinebetane on strewss tolerance, growth, and yield of spring cereals and summer turnip rape in Finland $J$. Agron. and Crop $S_{C} i . .176$ : 223-234.

Mäkelä, P., Munns, R., Colmer, T.D., Condon, A.G. and Peltonen-Sainio, P. (1998b). Effect of foliar applications of glycinebetaine on stomatal conductance, abscisic acid and solute concentrations of salt and drought stressed tomato. Australian J. Plant Physiol., 25:655-663.

McCuc, K.F. and Hanson, A.D. (1990). Drought and salt tolerance: towards understanding and application. TIBTECH. 8 : 358-362. 
McNeil, S.D., Rhodes, D., Russell, B.L., Nuccio, M.L., Shachar-Hill, Y. and Hanson, A.D. (2000). Metabolic modeling identifies key constraints on an engineered glycine betaine synthesis pathway in tobacco. Plant Physiol., 124 : 153-162.

Papageorgiou, G.C., Fujimura, Y. and Murata, N. (1991). Protection of the oxygenevolving photosystem II complex by glycinebetaine. Biochim. Biophys. Acta, 1057: 361-366.

Papageorgiou, G.C. and Murata, N. (1995). The unusually strong stabilizing effects of glycinebetaine on the structure and function of the oxygen-evolving photosystem II complex. Photosynthesis Res., 44 : 243-252.

Pocard, J.A., Bernard, T. and Le Rudulier, D. (1991). Translocation and metabolism of glycinebetaine in nodulated alfalfa plants subjected to salt stress. Physiol. Plantarum, 81 95-102.

Rajasekaran, L.R., Kriedemann, P.E., Aspinall, D. and Paleg, L.G. (1997). Physiological significance of proline and glycinebetaine - maintaining photosynthesis during $\mathrm{NaCl}$ stress in wheat. Photosynthetica, $34: 357-366$.

Rhodes, D. and Hanson, A.D. (1993). Quaternary ammonium and tertiary sulfonium compounds in higher plants. Ann. Rev. Plant Physiol. Plant Mol. Biol., 44 : 357-384.
Rohifs, E.M., Garner, S.C., Mar, M.H. and Zeisel, S.H. (1993). Glycerophosphocholine and phosphocholine are the major metabolites in rat milk. J. Nutrition. 123 : 1762-1768.

Saunderson, C.L. and Mackinlay, J. (1990). Changes in bodyweight, composition and hepatic enzyme activities in response to dietary methionine, betaine and choline levels in growing chicks. British J. Nutrition, $63: 339-349$.

Whapman, C.A., Blunden, G., Jenkins, T. and Hankins, S.D. (1993). Significance of betaines in the increased chlorophyll content of plants treated with seaweed extract. J. Appl. Phycology, 5:231-234.

Wu, Y., Jenkins, T., Blunden, G., Whapman, C. and Hankins, S.D. (1997). The role of betaines in alkaline extracts of Ascophyllum nodosum in the reduction of Meloidogvne javanica and $M$. incognita infestations of tomato plants. Fundam. Appl. Nematol. 20 : 99-102.

Wyn Jones, R.G. and Storey, R. (1981). Betaines. The Physiology and Biochemistry of Drought Resistance in Plants (eds. Paleg, L.G. and Aspinall, D.), Academic Press, Sydney, pp. 171-204.

Zuniga, G.E., Argandona, V.H. and Corcuera, L.J. (1989). Distribution of glycinebetaine and proline in water stressed and unstressed barley leaves. Phytochemistry, $28: 419-420$. 